\title{
A EXPANSÃO DA REPRESENTATIVIDADE DO "EU" NO Discurso AUTOBIOGRÁFICO DE JAMAICA KINCAID
}

\section{The expansion of self-representation in Jamaica Kincaid's autobiographical discourse}

\author{
Mail Marques de Azevedo*
}

$\mathrm{Na}$ introdução de My Garden (book) - obra que, apesar da indicação parentética do título, foi diversamente designada pela crítica como "mais que um jornal de jardinagem", "cornucópia fascinante", "visão da vida interior de uma jardineira particularmente introspectiva" - Jamaica Kincaid declara-se surpresa ao verificar que o jardim que estava fazendo ("que ainda está e que sempre estará fazendo") parecia um mapa do Caribe e do mar que o circunda:

[...] me espantei pela maneira como o jardim é para mim um exercício de memória; uma maneira de lembrar meu passado imediato, uma maneira de chegar a meu próprio passado (o Mar do Caribe) e ao passado que está indiretamente ligado a mim (a conquista do México e circunstâncias circundantes) (KINCAID, 2000a, p. xiv) ${ }^{1}$.

A observação acima resume o que se vai confirmar como o motivo central da obra de Jamaica Kincaid, sua relação espacial, temporal e afetiva com a pátria, com a família e com a cultura caribenha, a que subjaz toda uma preocupação com suas origens mais remotas, como representante feminina de um grupo conceitualmente designado como maioria alienada, denominação que se aplica a grupos culturais em contato, provenientes de diferentes regiões ancestrais, com tradições nativas diversas, e que não têm acesso às comunidades de origem, caso do que ocorre no Caribe (HOGAN, 2000, p. 317).

\section{* UNIANDRADE.}

${ }^{1}$ A tradução dos textos de Jamaica Kincaid, bem como dos textos de apoio, em citação direta, é de responsabilidade da autora. Como se trata de tradução não publicada, a indicação das fontes referese aos originais em língua inglesa. 
A incidência do possessivo em alguns títulos de obras de ficção e não ficção de Kincaid - At the Bottom of the River (1983), Annie John (1985), Lucy (1990), The Autobiography of My Mother (1996), o livro de memórias My Brother (1997), My Garden (1999) e Mr. Potter (2002) - vêm confirmar a ênfase na escritura e re-escritura de eventos retirados de sua própria experiência. Assim, sua ficção é povoada de personagens, cujos nomes de família, Potter e Richardson, remetem ao seu nome de batismo, Elaine Potter Richardson; ademais, a presença em todos os romances de uma protagonistanarradora em primeira pessoa - seu nome em Annie John (1985) estabelece vínculos com a mãe da autora Annie Richardson Drew, cuja neta foi batizada Annie em sua homenagem - reflete os conflitos e lutas que acompanharam Jamaica Kincaid em seu exílio da Antigua nativa, deflagrado principalmente pelo agravamento das condições financeiras das famílias, tanto na ficção como na vida real, com o nascimento de três irmãos homens.

É evidente a existência de um projeto autobiográfico subjacente à obra de Kincaid, mesmo que lhe faltem as características de uma autobiografia convencional, reconhecível, segundo Philippe Lejeune (1973), pela identidade narrador-personagem-autor, cujo nome figuraria na capa do livro, aspecto abertamente ignorado por Kincaid, em sua saga autobiográfica. Ao final de Annie John, a jovem heroína de dezesseis anos deixa Antigua, e no livro seguinte, a mesma personagem parece surgir em Nova Iorque, agora com o nome de Lucy, tendo a mesma relação definidora com o que parece ser a mesma mãe. A mudança de nome traça um movimento paralelo à vida da jovem Elaine Potter Richardson que, chegada aos Estados Unidos, também aos dezesseis anos, e, em busca de uma identidade própria, passa a chamarse Jamaica - nome que lembra o mundo de onde vem - e Kincaid, "por combinar com o nome anterior" (BIRBALSINGH, 1996, p. 140). A rejeição do nome que a identifica e subsequente escolha de outro que remete igualmente ao mundo do Caribe traduz a relação ambivalente de rejeição e de amor à mãe-pátria, presente também no relacionamento traumático das heroínas ficcionais com a mãe, representada tanto pela terra natal Antigua, como pela figura materna, trabalhada sempre em tom de conflito nos diferentes romances.

A publicação de The Autobiography of My Mother, em 1996, acrescenta ênfase contundente à manipulação livre dos limites entre autobiografia e ficção que caracteriza a obra de Kincaid. Pode-se presumir que o titulo é pronunciado na voz autobiograficamente construída de Kincaid, que insinua que o livro é autobiográfico nas idéias, mas não na situação (BERNARD, 2002, p. 121). À luz dessa declaração ambígua, Kincaid toma elementos da vida de sua mãe e de seus avós e organiza esses elementos em um tecido imaginativo que conta o passado de sua família materna. A narrativa em primeira pessoa narra a história de Xuela - a mãe ficcional de Kincaid - iniciando com a referência à morte da mãe da narradora ao dar à luz a menina, cuja vida é marcada pelas tentativas de construir sua própria identidade, apesar da perda física da mãe. Detalhes de relacionamento 
familiar, incidentes de plot, imagens e temas das obras anteriores se repetem no livro, que nos leva ao âmago da questão do relacionamento ambivalente da protagonista com a figura materna.

É óbvia a intenção de Kincaid de pôr em relevo o autobiográfico em sua obra, mas ela o faz em desafio ao compromisso do gênero com a representação do factual, ao atribuir experiências e sentimentos comuns a diferentes personagens - que partilham de traços biográficos e características da autora -, especialmente a relação conflituosa com suas origens. $O$ aspecto psicológico do relacionamento traumático mãe-filha, bem como seu significado como símbolo do conflito maior colonizador-colonizado, metrópole-colônia têm sido abordados em várias leituras da obra de Kincaid. Entretanto, partindo dessas mesmas considerações, é possível explorar mais a fundo a fluidez dos limites entre autobiografia e ficção em sua obra, enfocando seus romances como exemplo limítrofe do gênero autobiográfico, em que a representação do "eu" se expande para representar o "nós". É, portanto, nosso objetivo demonstrar que os paralelos entre a ficção e os fatos da vida de Kincaid, distribuídos ao longo de seus romances $A t$ the Bottom of the River (1983), Annie John (1985), Lucy (1990), The Autobiography of My Mother (1996) fazem de sua obra uma autobiografia extensiva, que narra não apenas a sua "vida individual", mas questiona os limites entre verdade e mentira, bem como os limites da representatividade, com a expansão compulsória do eu para representar outros, uma comunidade periférica em busca de identidade. Além disso, postulamos que o processo de busca da identidade, que acompanha o desenvolvimento das protagonistas da infância à adolescência e culmina com o exílio, constitui um bildungsroman coletivo de caráter mítico, em que se evidenciam as fases de separação - iniciação - retorno, apontadas por Joseph Campbell (1973, p.36) como a base do monomito do herói que percorre o mundo em busca da revelação final. A prosa poética de Kincaid, suas características de sonho e mistério emprestam fundamento a esta abordagem. A representação do eu na saga autobiográfica de Kincaid, opera, portanto, a distância das convenções da autobiografia.

$\mathrm{Na}$ realidade, estudiosos do gênero concordam que o discurso que pretende descrever uma história do eu tem evidente caráter ficcional: as autobiografias não são simples crônicas de fatos, mas a manipulação engenhosa de detalhes e acontecimentos que adquirem o status factual durante a construção de uma persona particular como sujeito do relato. Para Paul Eakin (1999), a autobiografia é o mais escorregadio dos gêneros literários: a questão se resume em como determinar os limites entre a criação literária e a "narrativa retrospectiva em prosa que uma pessoa real faz de sua própria existência, quando focaliza especialmente sua vida individual, sobretudo a história de sua personalidade", de acordo com a definição proposta por Philippe Lejeune (1973), no conhecido ensaio "O pacto autobiográfico". A mera confirmação da historicidade do referente - um indivíduo identificado por um nome -, deixaria de lado, contudo, considerações sobre a natureza 
dessa "pessoa real". Em contraposição, Eakin cita Michael Sprinkler, para quem a autobiografia é um local fundamentalmente instável, fluido, sem limites estabelecidos, onde "conceitos de sujeito, self, e autor se confundem no ato de produzir um texto". Em consequência, apesar das pretensões referenciais (o nome historicamente real partilhado pelo protagonista, pelo narrador e pelo autor do texto) a figura do eu permanece uma criatura de ficção. Sem um "eu" para realizar ações, para possuir sentimentos e qualidades, a possibilidade de "ter" uma história da própria existência para contar simplesmente se evapora. O sujeito da autobiografia é uma ficção. Diante do impasse conceitual entre a referencialidade do texto autobiográfico e o caráter fictício de seu sujeito, Eakin parte para a pergunta sobre o que tais textos nos ensinam sobre as maneiras pelas quais os indivíduos em uma determinada cultura experimentam o sentido de ser eu. Sua abordagem da natureza e fontes da identidade que os autobiógrafos reclamam baseiase na experiência. Embora haja um sentido legítimo em que as autobiografias atestam a experiência de identidade individual (selfhood) esse testemunho é necessariamente mediado por modelos culturais de identidade disponíveis e pelos discursos em que são expressos (EAKIN, 1999, p. 2-7).

De fato, Kincaid admite que ao procurar entender o relacionamento entre suas criaturas ficcionais - mãe e filha - e ao observar o poder da mãe e, eventualmente, sua autoridade em declínio, foi levada a uma visão mais ampla da relação colônia-metrópole. Conscientemente, confessa, deve ter considerado o seu relacionamento pessoal como uma sorte de protótipo da situação social mais abrangente que testemunhara (BIRBALSINGH, 1996, p. 144).

Seu primeiro livro At the Bottom of the River, em que se sobrepõem narrativa e poema em prosa - na avaliação de Harold Bloom (1998, p. vii), o gênero característico que Kincaid vem a desenvolver - introduz a jovem protagonista e narradora em primeira pessoa que pervade o conjunto de sua obra. No ritmo encantatório dos contos fantásticos infantis, a personagem recria um mundo íntimo particular inserido no panorama variegado do Caribe, a partir do brevíssimo conto "Menina", o primeiro do livro:

[...] é assim que você planta okra - longe de casa, porque a árvore de okra cria formigas vermelhas; quando plantar dasheen, não deixe de molhar bastante senão vai dar coceira na garganta quando a gente come; é assim que você varre os cantos; é assim que você varre a casa toda; é assim que você varre o quintal; é assim que você sorri quando não gosta muito da pessoa; é assim que você sorri quando detesta a pessoa; é assim que você arruma a mesa para o chá; é assim que você arruma a mesa para o jantar; é assim que você arruma a mesa para um jantar de convidados importantes; é assim que você arruma a mesa para o almoço; é assim que você arruma a mesa para o café; é assim que você se comporta na frente 
de homens que não conhecem bem você e desse jeito não vão perceber logo que você é a rameira que eu sempre te avisei que não fosse; não se esqueça de se lavar todos os dias, mesmo que seja com teu próprio cuspo; não se abaixe para jogar bola de gude - você não é um menino, tá?; não corte flores em jardins estranhos - você pode pegar alguma coisa; não jogue pedras em melros, porque pode não ser um pássaro; [...] É assim que se faz um bom remédio contra resfriado; é assim que se faz um bom remédio para jogar fora um filho antes mesmo que venha a ser um filho; [...] é assim que se provoca um homem; é assim que um homem provoca você; é assim que se ama um homem, e se não der certo, tem outras maneiras, e se não derem certo, não fique triste se tiver de desistir (KINCAID, 1992, p. 4-5).

Kincaid empresta à voz da menina, que repete para si mesma a ladainha de admoestações da mãe dominadora, um tom de protesto indignado, evidente no próprio ritmo da repetição, que se torna irritante: ao mesmo tempo em que se submete com relutância aos códigos de conduta maternos, a menina os solapa e ridiculariza. "Menina" contém o embrião do relacionamento conflituoso mãe-filha, que vem a constituir o núcleo temático da obra ficcional de Kincaid.

Outros contos do livro enfatizam a necessidade básica da protagonista-narradora em primeira pessoa de buscar a essência do seu eu. No decurso de uma de suas viagens-sonho, a protagonista, à semelhança do herói mitológico que mergulha no mundo subterrâneo, precipita-se em um buraco profundo e escuro que inopinadamente se abrira à sua frente, em busca da revelação escondida em seus recessos. Ao invés do conhecimento da ordem última das coisas, entretanto, a queda lhe traz profunda saudade das pessoas amadas. Desistindo da busca pessoal o eu narrador reverte para o horizonte materno: "Olhando novamente para o horizonte, vi uma figura solitária caminhando em minha direção, mas não senti medo; tinha certeza de que era minha mãe". Mas a experiência quase metafísica tem um desenlace anticlimático com a pergunta chã da mulher desconhecida: "Então é você. Quem diria. É você! Pode-se saber o que anda fazendo ultimamente?" (KINCAID, 1992, p. 42-43).

A imagem da queda no poço e consequente obliteração do eu repetese em Annie John. A incipiente maturidade sexual da menina de quinze anos atrai o insulto "rameira" da mãe obcecada com a preservação da virtude sexual, indispensável para a cotação da mulher no mercado matrimonial:

A palavra "rameira" (em patuá) foi repetida tantas vezes que de repente senti como se estivesse me afogando em um poço, cheio não de água, mas da palavra "rameira', que jorrava pelos meus olhos, meus ouvidos, minhas narinas, minha boca (KINCAID, 1985, p. 102). 
A recorrência de imagens é apenas um dos traços que emprestam à obra de Kincaid o caráter de uma única história de vida composta de narrativas diversas. Repetem-se tanto incidentes menores de plot-o episódio de um macaco que revida um ataque da protagonista-narradora causandolhe ferimento profundo na testa com a mesma pedra com que fora atingido -, como se reproduzem situações centrais da trama - a mãe trinta e cinco anos mais jovem que o pai e que tem de recorrer a obeah, para se defender de ataques das mulheres que se haviam relacionado com seu marido; a separação final da heroína, que procura no exílio a resposta a questões existenciais. Estaria Kincaid escrevendo seu próprio bildungsroman?

Em entrevista a Frank Birbalsingh, Kincaid admite, por exemplo, que Annie John corresponde até certo ponto à sua vida, mas também "é fiel a outras coisas, a um caminho que [sua] vida não tomou" (BIRBALSINGH, 1996, p. 138). O terceiro capítulo do livro oferece pistas para compreender o que Kincaid entende como escrita autobiográfica. Uma das primeiras tarefas escolares da menina, então com doze anos de idade, é um ensaio autobiográfico a ser lido diante de toda a classe. A descrição do relacionamento idílico mãe-filha, que encobre o atual estado de conflito entre Annie e a mãe, depois que se rompe a unidade pré-edipiana dos primeiros capítulos, funciona como uma metáfora do romance em sua totalidade, em que "mentiras" devem entrar na autobiografia quando esta se destina a um público.

A última parte não era bem uma mentira. É o que teria acontecido nos velhos tempos [...] Eu não tinha coragem de mostrar minha mãe sob uma luz desfavorável diante de pessoas que mal a conheciam. Mas a verdade era que eu não tinha coragem de mostrar aos outros que eu caíra em desgraça com minha mãe (KINCAID, 1985, p. 45).

Comentários de Jamaica Kincaid sobre o possível referente real de seus textos, em diversas entrevistas, confirmam o caráter autobiográfico de sua escrita - "Os eventos são verdadeiros para mim. Podem não ser verdadeiros para os outros". Ao propor uma narrativa que desestabiliza a verdade histórica, ela enfatiza a realidade construída da representação do eu: "Escrever exatamente o que aconteceu para mim tem valor limitado. Dizer exatamente o que aconteceu é menos do que o que eu sabia que aconteceu" (FERGUSON, 1993, p. 119).

$\mathrm{Na}$ construção da historia de vida de Annie, Kincaid explora os limites da perspectiva infantil. Ao invés de focalizar a infância do ponto de vista do adulto - como na autobiografia convencional -, mergulha o leitor na perspectiva misteriosa e imatura da criança sobre amor, morte, sexo, história e formação da identidade individual. No desenvolvimento do bildungsroman de suas personagens femininas, Jamaica Kincaid, do mesmo modo que outras escritoras oriundas de minorias étnicas, volta à figura 
materna para definição de sua vida, de sua história e de sua identidade.

A primeira fase, Annie John, é uma história de iniciação sobre as ações de uma menina, da infância em Antigua até uma relativa maturidade, quando vai para Londres, aos dezesseis anos, no final do romance. De certa maneira, a vida de Annie mal começou, mas seu aprendizado em Antigua foi uma preparação para a vida no mundo exterior. Além do forte elo matrilinear, o aspecto da cultura caribenha que prepara a jovem neófita para criar uma vida independente é a tradição de contar histórias, que enfatiza a importância da tradição oral para manter a identidade dos grupos que não têm acesso à sua cultura de origem. $O$ relacionamento com a mãe e a história de vida de Annie estão profundamente ligadas no romance. É a mãe que tece a malha da vida de Annie, como ilustra o ritual recorrente de examinar o conteúdo da arca em que se guardavam as roupas de Annie bebê, quando a mãe erguia uma peça de cada vez, recriando o passado da menina com relatos vívidos do que cada item significava: a roupa do batismo, mamadeiras, boletins escolares, o primeiro caderno, prêmios conquistados na escola - símbolos da menina e da mulher em que se transformaria:

Às vezes eu conhecia a história em primeira mão, pois me lembrava bem do acontecido; às vezes o que ela contava tinha acontecido quando eu era muito pequena para saber das coisas; às vezes, antes de eu nascer. Qualquer que fosse o caso, eu sabia exatamente o que ela ia dizer, pois já tinha ouvido as histórias muitas vezes, mas sem nunca me cansar (KINCAID, 1985, p. 21).

As narrativas tornam o passado tão real quanto o presente. O papel crucial da mãe de Annie na recriação do passado e sua influência na escritura de suas memórias repete-se no desenvolvimento da arte da escrita por Jamaica Kincaid, que afirma: "o modo como me tornei escritora foi que minha mãe escreveu minha vida por mim e contou minha vida para mim" (PERRY, 1998, p. 134).

As ideias de mãe como fonte da vida - alimento que nutre, sustenta, acalenta e adestra -, de pátria e de escrita formam uma tríade indissolúvel, essencial para a nurturance da personagem-criança e para o desenvolvimento de sua identidade, na traumática passagem para a adolescência, em que se agrava o conflito mãe-filha. Na perspectiva infantil, todos os atos da mãe, a exemplo da proibição de participar em jogos próprios de meninos, da destruição dos livros comprados com dinheiro roubado e escondidos debaixo da casa, que podemos ler como paralelos aos ordeals na fase de iniciação do neófito, assumem proporções épicas: "Minha mãe me mataria se tivesse oportunidade. E eu mataria minha mãe se tivesse coragem" (KINCAID, 1985, p. 89). Esse refrão, que acompanha as jornadas oníricas da personagem por largos caminhos sombreados de vegetação exuberante, representa a epítome do conflito mãe-filha, que leva finalmente ao exílio. Para Annie, trata-se de uma separação permanente, que a desliga 
dos pais e de tudo o que foi ou fez:

Tudo o que eu faria naquela manhã até chegar ao navio que me levaria para a Inglaterra seria pela última vez, pois eu tinha decidido que, não importa o que acontecesse, meu caminho seguiria uma única direção: para longe de meu lar, de minha mãe, de meu pai, do céu eternamente azul, do sol eternamente quente, de pessoas que me diziam: "Isto aconteceu quando sua mãe estava grávida de você” (KINCAID, 1985, p. 133-34).

O desabafo apaixonado da personagem retrata a relação contraditória e paradoxal de Kincaid com as entidades mãe e pátria, associadas em sua escrita na díade paraíso-mãe, não o Caribe maquilado como paraíso turístico, de onde, no entanto, "fogem todos os que podem" mas o local de origem de uma "espécie de momento benigno, maravilhoso, inocente que você partilha com aquele grande ente poderoso que, como você vem a descobrir, nunca vai te libertar" (BIRBALSINGH, 1996, p. 147).

Não é, portanto, o suposto paraíso caribenho a fonte de inspiração de Kincaid que, em $A$ Small Place, em tom de profunda revolta, traça um perfil cáustico das deficiências e deformidades de sua pátria, saldo cruel de séculos da dominação colonial inglesa, que lhes roubou a língua, a terra, o nome e as tradições (KINCAID, 2000b, p. 31).

Sua personagem Annie rebela-se igualmente contra os efeitos da colonização, porém de maneira mais sutil se comparada com a rebeldia agressiva contra a mãe: na aula de história, escreve sob o retrato de um Colombo melancólico, caído em desgraça com seus reais protetores "O grande homem não consegue mais se levantar e continuar" - as palavras exatas que a mãe de Annie usara para referir-se à decadência física do seu próprio pai, um tirano dominador. Como castigo, a menina é condenada a copiar dois capítulos do Paraíso Perdido, punição exemplar, que a mergulha na literatura do colonizador. O racismo que faz parte da vida nas Índias Ocidentais, a revolta e o ódio que originou são evidentes nas lembranças da narradora:

[...] às vezes, sob a influência de livros e professores, tornava-se difícil para nós dizer a que lado pertencíamos - com os senhores ou com os escravos - pois tudo era história, tudo estava no passado, e agora todos agiam diferente; todos nós comemorávamos o aniversário da Rainha Victoria, embora ela já tivesse morrido há muito tempo. Mas nós, descendentes de escravos, sabíamos muito bem o que tinha acontecido na realidade, e eu tinha certeza de que, se os papéis estivessem invertidos, teríamos agido de modo diferente; tinha certeza de que se nossos ancestrais tivessem ido da África para a Europa e encontrado o povo que vivia lá, teriam se interessado pelos europeus e dito "Que bonito", e voltado para casa para contar aos amigos (KINCAID, 1985, p. 76). 
Pertencer a dois mundos gera um conflito identitário que atinge a própria autora, em dificuldades para determinar quem é seu público leitor: falantes brancos de língua inglesa, que pouco interesse teriam a seu respeito - por sua origem colonial, filha de camponeses pobres -, ou seus conterrâneos de Antigua, de onde foi "banida" informalmente, em 1985, pelos adversários de sua escrita, considerada ofensiva. Nas palavras de Kincaid: "À medida que escrevo, me interesso cada vez menos pela aprovação do primeiro mundo, e como nunca tive a aprovação do mundo de onde venho, não sei bem onde estou. Sou mais uma vez uma exilada" (FERGUSON, 1993, p. 51).

A palavra exílio é fundamental para a saga autobiográfica criada por Kincaid, que continua em $L u c y$, cuja protagonista acrescenta uma nova camada ao bildungsroman coletivo, ao contar sua própria história, ao mesmo tempo em que reescreve temas familiares. Soa, ainda, aos ouvidos do leitor, o protesto doloroso de Annie, ao se despedir em definitivo da paisagem familiar. A rebeldia e o desejo de cortar todos os liames se esvaziam diante das palavras da mãe, que "laceram a sua pele": "Não importa o que você faça ou aonde você vá, eu sempre serei sua mãe e este será sempre o seu lar" (KINCAID, 1985, p. 147). É mais um obstáculo que o neófito deve superar no caminho em busca da revelação final.

As jornadas-sonho de Annie se concretizam no exílio efetivo que a conduz à Inglaterra - o caminho da maioria dos caribenhos em busca de uma identidade -, enquanto Lucy, numa ruptura radical, substitui a metrópole, e a consequente visão do sujeito colonial como estereótipo da submissão e do exotismo nativo, pelo exílio nos Estados Unidos, onde, segundo Kincaid, é possível "inventar uma voz e vê-la aceita como sua", despertando interesse "não por quem você é, mas pelo que tem a dizer" (BIRBALSINGH, 1996, p. 142).

A reação de Lucy à América, como símbolo do novo, é ambígua: a sensação de estranhamento lhe causa desconforto, à semelhança das roupas novas que veste, e, ao vivo, os lugares que costumavam povoar seus sonhos como "botes salva-vidas de sua alma", lhe parecem "comuns, sujos, gastos pela entrada e saída de tantas pessoas na vida real” (KINCAID, 1990, p. 4-5). O sol pálido de inverno não aquece e ela lembra com nostalgia o calor dos trópicos; pela primeira vez na vida, sente frio exterior e interior. Irrita-lhe que as pessoas vejam o Caribe simplesmente como um local onde se divertiram, mas, por outro lado, ela mesma não pretende retornar a um lugar que a sufoca. A separação geográfica rompe um elo físico, mas a profunda ligação entre Lucy e seu passado não pode ser rompida: "Eu pensava que somente mudando de lugar ficaria livre para sempre das coisas que mais desprezava. Mas não seria assim. A cada dia que passava, eu via o mesmo em tudo e o presente tomar forma - a forma do passado" (KINCAID, 1990, p. 90). Inconscientemente, Jamaica Kincaid reproduz o Caribe nos canteiros de seu jardim.

O romance $L u c y$ se desenvolve em Manhattan nos anos 60, pouco antes da independência parcial de Antigua, em 1967, aonde Lucy chega 
para trabalhar como au pair, com uma família americana de classe alta. Assim, a protagonista se vê cercada quase que exclusivamente por brancos, na casa em que trabalha e no círculo de amigos. Embora Lucy não sofra manifestações evidentes de racismo, Kincaid torna clara a perceptividade cultural da protagonista, empregando a estratégia de inversão: Lucy é ao mesmo tempo transformada em fetiche - todos procuram ser-lhe agradáveis - e tratada de forma condescendente, num arremedo das antigas relações de hierarquia entre colonizador e colonizado. Tanto os patrões de Lucy, como os amigos da família fingem ignorar as diferenças de raça e de classe que fazem parte de sua vida. Lucy não é enganada por esse procedimento, embora não o declare abertamente, e, desde o início, conscientemente ou não, dedicase a solapar todo tipo de autoridade e a afirmar seu direito de contestação.

Seu comportamento agressivo contra Mariah, a jovem patroa americana, marca a reação não só contra a autoridade materna, - "as vezes que eu amava Mariah era porque me lembrava minha mãe. As vezes que eu não amava Mariah era porque me lembrava minha mãe" (KINCAID, 1990, p. 58) - mas contra o paternalismo condescendente da classe hegemônica. Mariah é bondosa, compreensiva, sincera e mesmo ingênua em suas tentativas de se aproximar de Lucy. É ingênua sua declaração de que descende de índios, "como se anunciasse a posse de um troféu." A reação de Lucy é negativa "Que espécie de vencedor é esse que deseja também fazer parte dos vencidos?" (KINCAID, 1990, p. 41).

Rejeita igualmente os conselhos de Mariah para que escreva para a mãe em Antigua, cujas cartas recusa-se a abrir. A conquista da recompensa que aguarda o herói ao fim da jornada mítica - a maturidade e o conhecimento - torna-se cada vez mais fugidia para Lucy. Como na imagem da descida às entranhas, a figura da mãe se interpõe entre a heroína e a revelação final: "Chegara à conclusão de que o amor de minha mãe por mim destinava-se tão somente a me transformar num eco dela mesma, mas eu preferia estar morta a ser apenas o eco de alguém" (KINCAID, 1990, p. 36). Portanto, a jornada em busca do eu fica prejudicada pela impossibilidade de romper a ligação inexorável com a mãe. Que sua mãe não é outro, mas uma extensão do eu é a repetida afirmativa de Lucy, que dá voz a seu temor mais persistente:

Meu passado era minha mãe: eu ouvia sua voz, e ela me falava não em inglês ou no patuá de francês que às vezes usava, ou em qualquer linguagem que precisasse do auxilio da língua; ela me falava numa linguagem que qualquer mulher compreenderia. E não havia como negar o que eu era - mulher. Era para morrer de rir; eu passara tanto tempo dizendo que não queria ser como minha mãe, que não entendera nada da história: eu não era como minha mãe - eu era minha mãe (KINCAID, 1990, p. 90). 
A consciência da impossibilidade de romper com o passado é precedida por conflito íntimo cruel, por muitas tentativas de afastamento da díade pátria-mãe, que reserva à mulher um papel servil - dona de casa ou, quando muito, enfermeira -, enquanto atribui carreiras ilustres para os filhos homens:

Sempre que via seus olhos se encherem de lágrimas ao pensar no orgulho que sentiria com as realizações de seus filhos, eu sentia uma espada atravessar meu coração pois não havia um cenário paralelo em que ela me visse, o único rebento idêntico a ela, em uma situação remotamente semelhante (KINCAID, 1990, p. 130).

A revolta se concretiza no afastamento total, mas que não traz satisfação. Se ela tivesse lido as cartas da mãe, que permaneceram fechadas durante meses, "teria morrido". A notícia da morte do pai, - que poderia ter sido provocada pelo desejo expresso da criança "Nunca mais quero ver você" - desperta nela sentimentos de culpa: "Mas eu não me sentia uma assassina; eu me sentia como Lúcifer, condenado a cometer erro sobre erro" (KINCAID, 1990, p. 139).

Apesar de tudo, Lucy não volta atrás. Mantém a decisão do afastamento. Escreve para a mãe, enviando dinheiro com a promessa de voltar logo, mas manda-lhe um endereço falso e afasta-se também de Mariah, antes mesmo de completar um ano de seu compromisso de trabalho. Aos dezenove anos, sexualmente madura, busca sua própria satisfação física, mas não se envolve emocionalmente. É sempre ela que provoca o fim dos relacionamentos. Já não lhe pesa o epíteto "rameira", que a sociedade patriarcal impõe à mulher que se desvia de padrões de conduta estabelecidos, julgamento de que a mãe se faz porta-voz. Paradoxalmente, é a voz materna, instruindo-a no uso de "um bom remédio para jogar fora um filho antes mesmo que venha a ser um filho", que Lucy recorda para manter sua postura de liberdade e não envolvimento. A rejeição da maternidade - função primeira da mulher na sociedade patriarcal - integra a conquista do prêmio alcançado pela heroína, ao final da jornada mítica: a independência. Orgulhosa e apaixonada como Lúcifer, ela se transforma em uma nova pessoa, direta e extremamente honesta, que, mesmo assim, não se sente feliz:

Tinha agora a vida que sempre quisera. Longe de minha família, em um lugar onde ninguém sabia muito a meu respeito; quase ninguém sabia sequer o meu nome, e eu era mais ou menos livre para ir e vir à vontade. Mas não conseguia encontrar em meu íntimo a alegria, a felicidade, a sensação de um desejo atingido que eu esperava alcançar (KINCAID, 1990, p. 158).

O preço da independência é a renúncia ao amor: "Queria poder amar tanto alguém a ponto de morrer de amor" (p. 164), escreve sob seu 
nome Lucy Josephine Potter, grafado no alto da página branca, "suave como leite", do caderno de notas, presente de despedida de Mariah. Embora se dissolva em lágrimas, a ponto de borrar todas as palavras, fica nas últimas frases de Lucy a sugestão da escrita como veículo de criatividade e reprodução do eu que lhe trará identidade completa.

A posição ambígua quanto à identidade, pátria e família prevalece também na vida de Kincaid: "Sou tão vulnerável às necessidades de minha família que de vez em quando me afasto deles. Não escrevo, não visito, não minto, não nego, apenas me afasto", escreve ela no livro de memórias $M y$ Brother (1997b, p. 20). Por outro lado, corre em socorro do irmão condenado pela Aids, que não via desde os três anos de idade.

Pergunta-se, entretanto, até que ponto é válida a busca de comprovação dos eventos de um relato que se julga autobiográfico, à luz das considerações teóricas sobre o gênero. Lejeune (1973) delimita e sistematiza o gênero autobiográfico textualmente, a partir da posição do leitor: não se trata nem de partir da interioridade de um autor (a qual constitui justamente o problema), nem de estabelecer os cânones de um gênero literário. Ao partir da situação do leitor, que é a única que ele próprio como leitor conhece bem, tem a oportunidade de captar com mais clareza o funcionamento dos textos, uma vez que foram escritos para os leitores, e que é o leitor que os faz funcionar.

A questão da autobiografia não se coloca, para Lejeune, como uma relação estabelecida entre eventos extratextuais e sua transcrição "verídica" pelo texto, mas em uma espécie de acordo entre quem lê e acredita estar diante de revelações verdadeiras da vida íntima do autor, e quem escreve e deve manter o compromisso com a veracidade das revelações - o pacto autobiográfico.

$\mathrm{Na}$ realidade, como procuramos demonstrar, Kincaid desvia-se propositalmente da demanda do pacto - contar literalmente a verdade -, ao fazer uma utilização sui generis do autobiográfico, a fim de atingir seu objetivo: criar um novo discurso mais adequado para reportar a verdade e a identidade de um sujeito pós-colonial. Começa por desviar-se da exigência primordial para o reconhecimento de uma autobiografia, segundo Lejeune, a identificação autor-narrador-personagem, que o texto mantém deliberadamente dúbia. O sobrenome Potter é comum a Lucy e a Kincaid, que se desfaz do nome próprio e do nome de família, em seu périplo em busca de uma identidade própria; Lucy recorda que, na ânsia "de se reinventar" (KINCAID, 1990, p. 134), tentara despojar-se do nome próprio que a identifica. Neste aspecto, repete a escolha feita por Annie John de um novo nome, Enid, sugerido pelas leituras da romancista inglesa Enid Blyton. A escolha ilustra os obstáculos que o sujeito colonial encontra na busca de uma identidade própria: politicamente a obra de Enid Blyton é uma defesa do império; na vida pregressa das personagens, o nome Enid evoca uma das ex-amantes do pai que usa obeah contra a vida da protagonista e de sua mãe. 
Como se observa, a obra de Kincaid reconfigura os imperativos literários da intertextualidade, pois ao invés de colocar seu trabalho em diálogo com o de outros autores, estabelece referências cruzadas entre seus próprios textos. É na organização taxonômica deste autoinventário e das conexões que emergem entre suas vozes ficcional e não ficcional que Kincaid força os limites da autobiografia e da memória, o que se torna mais evidente em The Autobiography of My Mother. A voz da narradora Xuela Claudette Richardson, de 70 anos de idade, rememora os acontecimentos em um monólogo sem interação com outras personagens, cujas vozes são intermediadas pela sua. Xuela, que representa a mãe ficcional de Kincaid, inicia a narrativa com referência à morte de sua própria mãe -, isto é, da avó ficcional de Kincaid -, ao lhe dar à luz: "Minha mãe morreu no momento em que nasci, e durante toda a minha vida existiu apenas o nada entre mim e a eternidade; às minhas costas sempre soprou um vento soturno e negro" (KINCAID, 1997a, p. 3). Como corolário, a recusa de Xuela de se tornar mãe, no decorrer da narrativa, pressupõe a negação da própria existência de Kincaid no "mundo real":

\begin{abstract}
Este relato de minha vida é um relato da vida de minha mãe tanto quanto da minha, da mesma forma que é um relato da vida dos filhos que não tive, como é um relato de mim. Em mim está a voz que nunca ouvi, o rosto que nunca vi, o ser de onde provenho. Em mim estão as vozes que deveriam provir de mim, as faces que nunca permiti que se formassem, os olhos que nunca permiti que me vissem. Este relato é um relato da pessoa a quem nunca se permitiu ser e um relato da pessoa que eu não permiti a mim mesma me tornar (KINCAID, 1997a, p. 227-8).
\end{abstract}

Não seria mais simples, diante da evidência da descontinuidade, considerar The Autobiography of My Mother meramente um exemplo de ficção autobiográfica, de tom apaixonado, que a autora lhe imprime quando reconstrói o ambiente de onde provém? Kincaid nos dá pistas que é impossível ignorar: o nome de família Richardson; a comunhão íntima mãe-filha que constituem um único ser, já estabelecida em Annie John e Lucy; a recorrência de aspectos de relações familiares que embaralham elementos de ficção - a irmã/tia aleijada e estéril - e realidade - a morte do irmão, vitimado por moléstia misteriosa; a repetição de incidentes menores de plot, como o episódio do macaco, e, principalmente, a temática central de busca da identidade da personagem-narradora, como sujeito feminino pós-colonial, elevada à dramaticidade máxima no relato da órfã sem raízes. É um caso de experimentalismo autobiográfico, comparável à Autobiografia de Alice Toklas, em que Gertrude Stein faz um relato em terceira pessoa, utilizando a persona de sua companheira, de seus próprios questionamentos sobre identidade pessoal e criação literária. 
O que se observa em todos os romances de Kincaid é o profundo sofrimento da personagem em seu desenvolvimento desde a infância até o exílio, evidente na transformação da relação de amor em ódio em Annie John; no desapontamento e no desconforto provocados pela realidade do novo em Lucy; no mergulho na identidade da mãe morta, em The Autobiography of My Mother. Na tese de Leigh Gilmore (2001, p. 96-98), Jamaica Kincaid quebra os limites da autobiografia ao representar um trauma psíquico. Sua narrativa é um testemunho de como a representação do eu (selfrepresentation) e a representação do trauma vão além de simples relação de causa e efeito, excedem sua duração no tempo e estabelecem ligação com outras formas de dor histórica, familiar e pessoal. No seu movimento de uma forma abertamente testemunhal - a autobiografia convencional -, para outra de caráter propositalmente ficcional, textos como os de Kincaid produzem meios alternativos de confrontar questões da relação entre pais e filhos, da violência e da representação do eu.

Em contraste com o autobiógrafo, preso por leis tradicionais de gênero literário, Kincaid procura, nas técnicas do gênero autobiográfico, os espaços que lhe permitem criar uma experiência de autobiografia em série, que ao invés de representar apenas um $e u$ individualizado se expandem para representar o nós. Kincaid re-escreve a continuidade ilusória da autobiografia, para examinar suas origens e sua identidade, embora se trate de um processo doloroso. "Compreendo por que as pessoas mentem sobre o passado [...] por que inventam um eu totalmente diferente do que são na realidade, por que desejariam sentir que não pertencem a nada nem descendem de ninguém, apenas caíram do céu, prontos" é o seu desabafo apaixonado no livro de memórias My Brother (1997b, p. 3).

Aplica-se a Kincaid a afirmativa de Paul Eakin de que "a escrita de autobiografia é [...] parte integral de um processo de formação de identidade que dura uma vida inteira e em que atos de autonarratividade têm papel primordial" (1999, p. 101). O processo de formação de identidade ainda não se encerrou para Jamaica Kincaid. Profissionalmente, depois de sua chegada aos Estados Unidos, foi free-lance reporter para várias revistas, dedicou-se á fotografia, e foi membro do staff da revista New Yorker. Tem dois filhos e recentemente divorciou-se do marido Allen Shaw, filho do editor de New Yorker. Sua conversão ao judaísmo é ilustrativa de sua busca de novos horizontes.

É impressionante como Kincaid se identifica com o grito de liberdade que conclui as narrativas de Annie John e Lucy. Saltam aos olhos seu desejo de independência, não conformismo e o destemor com que enfrenta situações, concretizados na busca incessante e na dedicação a seus ideais de liberdade intelectual, com a rejeição de rótulos e ligações. Não aceita ser incluída em tradições criticas ou literárias, a ser classificada de West Indian, feminista, ou pós-colonial e afirma que "não pode suportar estar em um grupo de qualquer espécie ou na escola de seja lá o que for" (CUDJOE, 1990, p. 221). 
Exemplarmente, recusa-se a considerar sua conversão ao judaísmo como identificadora: "Não escrevo sobre o fato de ser negra, ou de pertencer ao judaísmo, porque não acredito nessa espécie de identidade de grupo. Nunca integrei ser de Antigua, negra, mulher, ou judia. Isto não deveria impedirme de olhar para o sofrimento de outras pessoas. Não acredito que tenha me convertido ao judaísmo para separar o sofrimento dos judeus do sofrimento dos não judeus" (KINCAID apud LEV-ARI, 2003). Kincaid é profundamente sincera e cônscia das escolhas que faz, independente do sofrimento que possa causar a si própria.

Unido por um núcleo central - a necessidade de quebrar o relacionamento obsessivo com a mãe, da mãe como fonte de amor e como objeto de repúdio por simbolizar poder, autoridade e dominação, o conjunto da obra ficcional de Kincaid constitui, a nosso ver, uma única historia que retorna constantemente à matéria prima do eu, a fim de concluir como o self pode ser recriado. Como conclusão da jornada mítica, Annie John, transmudada em Lucy, atinge seu ideal de liberdade - a recompensa final -, mesmo que acompanhada de renúncia e sofrimento, num paralelo claro ao caminho de sua criadora, cujo lirismo, mais evidente no original inglês, traduz o ideal da busca incessante da transmutação:

I had no name for the thing I had become, so new was it to me, except that I did not exist in pain or pleasure, east or west, or north or south, or up or down, or past or present or future, or real, or not real. I stood as if I were a prism, many-sided and transparent, refracting and reflecting light as it reached me, light that never could be destroyed. And how beautiful I became (KINCAID, 1985, p. 80$)^{2}$.

\section{RESUMO}

Esse trabalho examina textos da escritora afro-caribenhaamericana Jamaica Kincaid - At The Bottom of the River, Annie John, Lucy, The Autobiography of My Mother - como exemplos limítrofes do gênero autobiográfico, em que a representação do "eu" se expande para representar o "nós". Considerando os limites entre autobiografia e ficção e como a representação do eu em romances autobiográficos opera a distância das convenções da autobiografia, analisa-se o relacionamento mãe-

\footnotetext{
${ }^{2}$ Eu não tinha um nome para aquilo em que me transformara, tão novo para mim, exceto o não existir na dor ou no prazer, a leste ou a oeste, ao norte ou ao sul, em cima ou em baixo, no presente ou no futuro, no real ou no irreal. À semelhança de um prisma eu me mantinha multifacetada e transparente, refratando e refletindo a luz que me alcançava, luz que nunca poderia ser destruída.
} 
filha extremamente traumático e doloroso que perpassa os textos como uma analogia da relação colonizador-colonizado. A construção de uma nova identidade livre de qualquer autoritarismo, no conjunto das narrativas, comparado a um bildungsroman de caráter mítico, simboliza a recompensa final da busca.

Palavras-chave: Jamaica Kincaid; ficção e autobiografia; relação mãe-pátria.

\begin{abstract}
This study examines some works by the Afro-CaribbeanAmerican writer Jamaica Kincaid - At The Bottom of the River, Annie John, Lucy, The Autobiography of My Mother - as threshold examples of the autobiographical genre, in which representation of the "I" is expanded to include the "us". Considering the limits between autobiography and fiction and how self-representation deviates from the conventions of autobiography in autobiographical novels, it analyzes the extremely traumatic and painful mother-daughter relationship throughout the texts, as an analogy to the colonizer-colonized relations. The construction of a new identity free of authoritarian influences symbolizes the ultimate reward in the set of selected works, read as a bildungsroman of mythical proportions.

Keywords: Jamaica Kincaid; fiction and autobiography; mother-country relationship.
\end{abstract}

\title{
REFERÊNCIAS
}

BERNARD, Louise. Countermemory and Return: Reclamation of the (Postmodern) Self. In: KINCAID'S, Jamaica. Autobiography of My Mother and My Brother. MFS Modern Fiction Studies, v. 48, n. I, p. 113-138, Spring 2002.

BLOOM, Harold (Ed.). Jamaica Kincaid. Philadelphia: Chelsea Hose Publishers, 1998.

BIRBALSINGH, Frank (Ed.). Frontiers of Caribbean Literature iun English. New York: St. Martin's Press, 1996.

CAMPBELL, Joseph. The Hero With a Thousand Faces. Princeton: Princeton Un. Press, 1973.

CUDJOE, Selwyn (Ed.). Caribbean Women Writers: Essays from the First International Conference. Wellesley: Calaloux, 1990.

EAKIN, Paul. How Our Lives Become Stories. Ithaca: Cornell Un. Press, 1999.

FERGUSON, Moira. Colonialism and Gender: From Mary Wollstonecraft to Jamaica Kincaid. New York: Columbia Un. Press, 1993. 
GILMORE, Leigh. The Limits of Autobiography. Trauma and Testimony. Ithaca: Cornell Un. Press, 2001.

HOGAN, Patrick Colman. Colonialism and Cultural Identity. New York: State University of New York Press, 2000.

KINCAID, Jamaica. Annie John. New York: Farrar, Straus and Giroux, 1985. . The Autobiography of My Mother. New York: Plume, 1997a. . At the Bottom of the River. New York: Plume, 1992. . Lucy. New York: Farrar, Straus and Giroux, 1990. . My Brother. New York: Farrar, Straus and Giroux, 1997b. . My Garden (book). London: Vintage, 2000a. . "She doesn't see in black and white: An Interview." In: Lev-Ari, Shiri. Tel Aviv, 2003. . A Small Place. New York: Farrar, Straus and Giroux, $2000 \mathrm{~b}$.

LEJEUNE, Philippe. Le pacte autobiographique. Poétique, v. 4, n. 14, p. 137-162, 1973. PERRY, Donna. Initiation in Jamaica Kincaid's Annie John. In: BLOOM, Harold (Ed.). Jamaica Kincaid. Philadelphia: Chelsea House Publishers, 1998. p. 131-139.

Submetido em: 10/09/2008.

Aceito em: 15/09/2009. 